in vivo $35: 1235-1245(2021)$

doi:10.21873/invivo.12374

\title{
Transanal Endoscopic Microsurgery (TEMS) for Rectal Cancer: Patient Decision-making, Postoperative Experience and Quality of Life
}

\author{
ALEXANDRA KORELI ${ }^{1,2}$, GEORGE BRIASSOULIS ${ }^{3}$, MICHAIL SIDERIS $^{4}$, \\ ANASTAS PHILALITHIS ${ }^{5}$ and SAVVAS PAPAGRIGORIADIS ${ }^{6}$ \\ ${ }^{1}$ Medical School, University of Crete, Heraklion, Greece; \\ ${ }^{2}$ Nursing Department, University of West Attica, Athens, Greece; \\ ${ }^{3}$ Medical School, University of Crete, Heraklion, Greece; \\ ${ }^{4}$ King's College Hospital, Denmark Hill, London, U.K.; \\ ${ }^{5}$ Medical School, University of Crete, Heraklion, Greece; \\ ${ }^{6}$ King's College Hospital, Denmark Hill, London, U.K.
}

\begin{abstract}
Background/Aim: Transanal endoscopic microsurgery (TEMS) is a form of minimally invasive surgery for selected rectal cancers. The aim of this study was to explore the factors affecting patients' decision-making concerning the choice of surgical treatment as well as to measure the Quality of Life (QoL) post-TEMS. Patients and Methods: Thirty-four patients with rectal cancer stage T1/T2 -NO-MO that underwent TEMS were studied. The questionnaires used included the Short Form SF12v2, Wexner Score (CCF-FIS) and the Sexual Function Questionnaire (SFQ). The patients'views on experience and treatment decision were obtained with a custom-designed questionnaire. Questionnaires were completed at a mean of 6.9 years following treatment. Results: The factors that influenced the patients' decisions were: experience satisfaction $(p=0.003)$, postoperative bowel function $(p<0.001)$, lower incontinence score $(p=0.020)$ and agreement of TEMS experience with preoperative information $(p=0.049)$. Treatment experience satisfaction was associated with family support $(p=0.034)$ and agreement with preoperative information $(p=0.047)$, better bowel function $(p=0.026)$ and mental QoL (MCS) ( $p=0.003)$. Conclusion: factors important to patients when reflecting on
\end{abstract}

This article is freely accessible online.

Correspondence to: Alexandra Koreli, 20 Salaminos, Agia Paraskevi, 15343, Athens, Greece. Tel: +30 6936001672, e-mail: alkor2004@yahoo.co.uk; akoreli@uniwa.gr

Key Words: Decision-making, rectal cancer, TEMS, QoL, geriatric, incontinence, sexual functioning treatment experience are adequate and reliable information, a good QoL and the presence of family support. Clinicians should incorporate those parameters in their practice when assisting patients in making a surgical treatment choice and provide informed consent on TEMS for rectal cancer.

Colorectal cancer (CRC) is the third most common cancer in men and second in women, globally (1), with the highest incidence of $44 \%$ in people over 75 years of age (2), and survival rates around $60 \%$ for 10 years or more for rectal cancer alone (3).

Rectal cancer (RC) is an important subgroup of colorectal cancer (CRC): it may result from different gene alterations (4) and its treatment is surgically more challenging. The "gold standard" of RC treatment is total mesorectal excision (TME) by either low anterior resection (LAR) or by abdominoperineal resection (APR) of the rectum with temporary ileostomy or a permanent stoma, respectively (5). Both operations are associated with significant morbidity (6). Sexual and bladder dysfunction, and the impairment of anal sphincter function impact patients' QoL following treatment $(7,8)$. Physical, social and emotional functions among patients are worse compared to the general population (7) while in older adults this may cause the loss of their social autonomy $(9,10)$.

An alternative to TME is the minimally invasive transanal endoscopic microsurgery (TEMS), which was introduced by Buess (11) in the early 1980s for selected early rectal cancers (ERC). The advantages of TEMS, apart from preserving the sphincters and the rectal function, are fast recovery and a shorter hospitalization (average 2 days) with much lower morbidity and mortality than LAR and APR $(12,13)$. TEMS has gained gradual acceptance and inclusion in international 
Table I. Research instruments: SF12v2, Wexner score, SFQ and TEMS evaluation questionnaire.

\begin{tabular}{|c|c|c|}
\hline Scale & Items & Score range \\
\hline SF-12v2 & $\begin{array}{l}12 \text { questions, } 8 \text { domains (physical functioning, role-physical, bodily pain, general health, } \\
\text { vitality, social functioning, role-emotional and mental health). } \\
2 \text { summary measurements: the physical component summary (PCS) and the mental } \\
\text { component summary (MCS) }\end{array}$ & $0-100$ \\
\hline $\begin{array}{l}\text { Wexner Score } \\
\text { (CCF-FIS) }\end{array}$ & $\begin{array}{l}5 \text { questions: incontinence to solid, fluid and gas, lifestyle; parameters highest score } \\
\text { represents the worst outcome }\end{array}$ & $\begin{array}{l}0-4 / \text { question } \\
0-20 \text { total }\end{array}$ \\
\hline \multirow{3}{*}{$\begin{array}{l}\text { Sexual Functioning } \\
\text { Questionnaire (SFQ) }\end{array}$} & 2 multi scales: Sexual functioning and the Medical impact & 9 sub-scales add up \\
\hline & $\begin{array}{l}\text { Sexual functioning scale: } 9 \text { subscales: Interest, Desire, Arousal, Orgasm, Satisfaction, } \\
\text { Activity, Relationship, Masturbation and Problems (male/female versions) } \\
\text { Point-scale: } 6,7 \text { and } 11 \\
\text { The Medical/Treatment Impact Scale: }\end{array}$ & $\begin{array}{l}\text { The higher score }= \\
\text { better function. }\end{array}$ \\
\hline & $\begin{array}{l}5 \text { items: } 4 \text { assess the impact of illness or treatment on sexual functioning and } \\
1 \text { assesses the adjustment to the condition } \\
\text { point-scale } 6 \text { and } 11\end{array}$ & $\begin{array}{l}\text { The higher score }= \\
\text { greater impact of } \\
\text { the treatment } / \text { medical } \\
\text { condition }\end{array}$ \\
\hline TEMS & 4 sections: & Responses as: \\
\hline Evaluation & Choice and decision on treatment: 4 questions & yes/no, \\
\hline Questionnaire & $\begin{array}{l}\text { Service-referral evaluation: } 8 \text { questions } \\
\text { Patient experience of TEMS surgery: } 6 \text { questions. } \\
\text { Current symptoms: } 7 \text { questions: }\end{array}$ & $\begin{array}{l}\text { better-worse, } \\
\text { less-more on } \\
\text { a } 3-, 4-\text { and } \\
11 \text {-point scale }\end{array}$ \\
\hline
\end{tabular}

SF12v2: Short Form 12v2; Wexner Score (CCF-FIS): Cleveland Clinic Florida Faecal Incontinence Score.

guidelines for the local excision of low-risk early-stage cancer $(5,14)$. The TEMS technique for ERC was shown to be safe with low local recurrence, high survival rates $(13,15)$ and equal oncological results with radical surgery (16-18). Although there are reports suggesting that the local recurrence rate after TEMS is higher compared to radical surgery (17, 18 ), in $90 \%$ of those cases "salvage surgery" with LAR/APR can be curative and the final mortality is no different compared to initially performed radical surgery $(19,20)$.

Hence, the decision regarding treatments that are similar in clinical and oncological outcomes rely on patient experience and QoL following treatment. Furthermore, in older and frail patients the surgical trauma should be kept to a minimum (9) with organ preservation, aiming for functional advantages and better QoL. Only few studies have addressed the QoL after TEMS with small samples and follow-up up to one year in most cases. The findings show that QoL returns to pro-TEMS levels in one year postoperatively and faecal continence seems to be affected temporarily $(21,22)$. Some aspects of QoL are better in TEMS patients than in TME (23), but the overall QoL compared to general population is found to be similar $(21,23)$. Nonetheless, it is not clear what QoL patients have after TEMS (24), and to which extend it justifies their treatment decision.

Patient involvement in treatment decisions is fundamental in modern health care and known to be beneficial to patient experience $(25,26)$. To the best of our knowledge, there is no literature regarding factors influencing patient decision- making towards the TEMS option against radical surgery. The aims of this study were to explore factors affecting patients' decision-making in choice of surgical treatment and to measure the QoL post-TEMS.

\section{Patients and Methods}

This study was conducted in a tertiary Coloproctology Unit at King's College Hospital, London, which is a center of excellence in TEMS. Patients were prospectively registered and followed up in a secure database. Prior to circulation of any study material, we identified deceased patients via our database, as well the electronic patients records (EPR). A unique identifier was given to each eligible individual, and all relevant clinical details were assigned to it in order to ensure data confidentiality. A separate anonymized list of eligible patients was created that included demographics and clinical data.

Sample. Participants were patients with confirmed diagnosis of stage T1-T2 -N0-M0 rectal cancer who underwent TEMS from 2002 to 2012. The inclusion criteria were patients who were operated with curative intent and also had a minimum of 3 years follow-up. We excluded patients who had recurrence after local excision (those were submitted to "salvage surgery") or high-risk pathology of the excised tumour specimen (those were submitted to "completion surgery"). All operations on patients enrolled in the study were performed by the same specialist surgeon (author SP).

Ethics. This study was granted permission by the NHS Lothian Research Ethics Committee (Protocol number REC reference: 15/SS/0077); it has also been approved by the local Ethics 


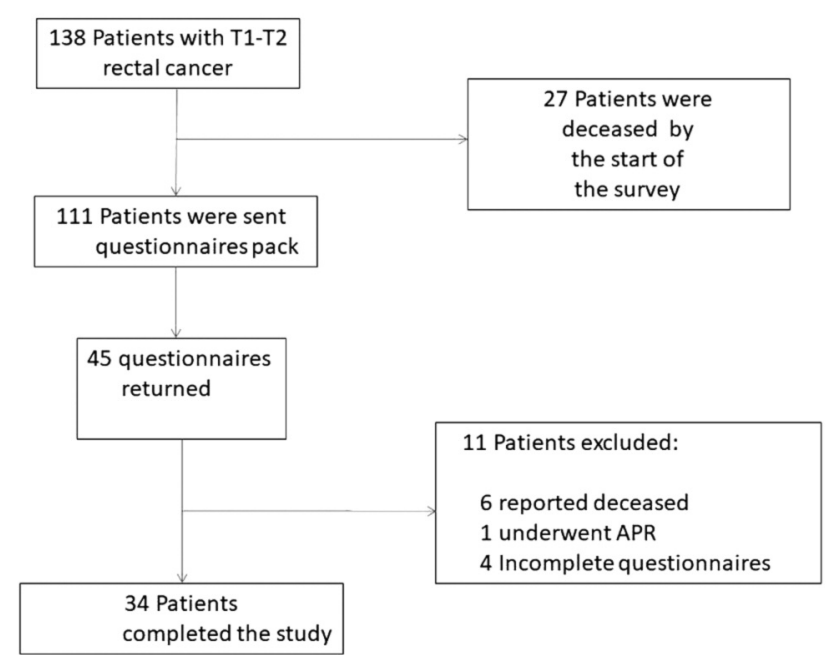

Figure 1. Process of data collection.

Committee of King's College Hospital NHS Foundation Trust: Registration $\mathrm{KCH} 15-180$.

Instruments. We used three validated questionnaires for assessing QoL, bowel continence and sexual functioning: SF-12 - version 2.0 (27), Cleveland Clinic Florida Faecal Incontinence Score CCF-FIS (Wexner Score) (28) and Sexual Functioning Questionnaire (29). In addition, for the purpose of the study a questionnaire was specifically designed regarding patients' TEMS experience and reflection upon the choice and decision of treatment. These questionnaires are described in Table I.

Data collection. Data was collected over 3 months. Initially we prepared a research pack of 4 questionnaires, where each pack was assigned a unique ID. The questionnaire pack with an explanatory cover letter and a pre-paid envelop was posted to eligible candidates. To achieve an increase in the response rates, 4 weeks later a reminder was sent out. Consent was implied by the participants returning the questionnaire.

Statistical analysis. We applied simple descriptive statistics to describe our results, which followed each questionnaire's manual scoring; missing data were handled according to the provided guidelines. Normality was tested using the Kolmogorov-Smirnov test. Normally distributed numerical variables were expressed as mean (standard deviation) while variables with skewed distribution were expressed as median (interquartile range). Qualitative variables were expressed in absolute and relative frequencies. For the comparison of continuous variables between two groups, a Student's $t$-test or Mann-Whitney $U$-test was used, as appropriate. Pearson's or Spearman's correlation coefficients were used to explore the association of two continuous variables. Correlation coefficients between 0.1 and 0.3 were considered low, between 0.31 and 0.5 moderate and those over 0.5 were considered high. Data were modelled using multiple linear regression analyses; the SFQ subscales and the overall score were the dependent variables. The regression equation included terms for gender, age, time of followup, Wexner score, PCS and MCS, as well as terms concerning the
Table II. Patients' characteristics, SF12v2, Wexner and SFQ scores.

\begin{tabular}{lc}
\hline Sample characteristics & \\
\hline Age of assessment (years), mean (SD) & $75.6(8.2)$ \\
Age of surgery (years), mean (SD) & $68.2(8.5)$ \\
Time of follow-up (years), mean (SD) & $6.9(2.0)$ \\
Gender, N (\%) & \\
Men & $22(64.7)$ \\
Women & $12(35.3)$ \\
Wexner Score, mean (SD) & $3.97(3.86)$ \\
Levels of continence and scores, N (\%) & \\
Perfect=0 & $7(20.6)$ \\
Good=1-7 & $21(61.8)$ \\
Moderate=8-14 & $5(14.7)$ \\
Severe incontinence=15-20 & $1(2.9)$ \\
SF-12v2 Scores & \\
PCS, mean (SD) & $44.4(12.0)$ \\
MCS, mean (SD) & $49.3(10.9)$ \\
SFQ subscales & \\
Interest, median (IQR) & $1.25(0-1.88)$ \\
Desire, median (IQR) & $1(0-2)$ \\
Arousal, median (IQR) & $0.25(0-1.25)$ \\
Orgasm, median (IQR) & $0(0-2.83)$ \\
Satisfaction, median (IQR) & $0(0-2.5)$ \\
Activity, median (IQR) & $0(0-0.88)$ \\
Relationship, median (IQR) & $4(2.5-4.4)$ \\
Masturbation, median (IQR) & $0(0-1.33)$ \\
Problems, median (IQR) & $0.75(0-3.75)$ \\
Overall SFQ score, median (IQR) & $1.33(0.67-2.2)$ \\
Medical Impact, median (IQR) & $2.75(2-3.5)$ \\
\hline
\end{tabular}

PCS: Physical component summary; MCS: mental component summary; SFQ: sexual functioning questionnaire.

patients' present symptoms. Regression coefficients $(\beta)$ with standard errors (SE) were computed from the results of the linear regression analyses using logarithmic transformation due to the lack of normal distribution of the dependent variables, using the stepwise method ( $p$ for entry $0.05, p$ for removal 0.10 ). All reported $p$-values are twotailed. Statistical significance was set at $p<0.05$ and analyses were conducted using SPSS (version 19.0, IBM, NY, USA).

\section{Results}

Out of 138 cases identified from a primary search on EPR from 2002 to 2012, 34 patients completed the questionnaires, a response rate of $31 \%(34 / 111)$. The process of data collection is presented in Figure 1.

The mean follow-up time was 6.9 years $(\mathrm{SD}=2.0)$, ranging from 4 to 12 years. The mean age of the study population was 75.6 years $(\mathrm{SD}=8.2)$ and the mean age at surgery was 68.2 years $(\mathrm{SD}=8.5)$. The male: female ratio was $22 / 12$. Sample basic characteristics and instrument scores are summarized in Table II. Non-respondents' $(n=66)$ characteristics did not differ from respondents: mean age was 76.7 years $(\mathrm{SD}=12.5)$, while mean age at surgery was 69.2 years $(\mathrm{SD}=12.2)$ and the follow up mean was 7.0 years $(\mathrm{SD}=2.0)$. 
Table III. Comparison of Quality of Life scores with the general UK population.

\begin{tabular}{|c|c|c|c|c|c|c|c|}
\hline & \multicolumn{3}{|c|}{ Present study } & \multicolumn{4}{|c|}{ UK normative ${ }^{a}$} \\
\hline & $\mathrm{N}$ & Mean & $\mathrm{SD}$ & $\mathrm{N}$ & Mean & $\mathrm{SD}$ & $p$-Value \\
\hline \multicolumn{8}{|c|}{ Physical score SF12 (PCS) } \\
\hline Total sample & 34 & 44.4 & 12.0 & 8204 & 50,0 & 9,7 & 0.001 \\
\hline Men & 22 & 41.1 & 12.3 & 3715 & 51,2 & 9,2 & $<0.001$ \\
\hline Women & 12 & 50.6 & 8.9 & 4446 & 49,0 & 10,0 & 0.588 \\
\hline \multicolumn{8}{|c|}{ Mental score SF12 (MCS) } \\
\hline Total sample & 34 & 49.3 & 10.9 & 8204 & 50,0 & 9,7 & 0.667 \\
\hline Men & 22 & 48.9 & 11.0 & 3715 & 51,4 & 8,9 & 0.186 \\
\hline Women & 12 & 50.0 & 11.5 & 4446 & 49,0 & 10,2 & 0.729 \\
\hline
\end{tabular}

aJenkinson and Layte, 1997 (49); Bold values indicate statistical significance.

Quality of life. The mean physical QoL of the studied population was lower compared to the UK general population: $44.4(\mathrm{SD}=12.0) v s .50 .0(\mathrm{SD}=9.7), p=0.001$. The male physical QoL was lower than in the general population: $41.1(\mathrm{SD}=12.3)$ vs. $51.2(\mathrm{SD}=9.2), p<0.001$.

The mental QoL of the study population was comparable to the general UK population: $49.3(\mathrm{SD}=10.9)$ vs. 50.0 $(\mathrm{SD}=9.7), \quad p=0.667$. No differences were found in comparisons adjusted for sex: male $48.9(\mathrm{SD}=11.0)$ vs. 51.4 $(\mathrm{SD}=8.9), \quad p=0.186$; female $50.0 \quad(\mathrm{SD}=11.5) \quad v s .49 .0$ ( $\mathrm{SD}=10.2), p=0.729$ (Table III).

Similar results were found when compared to the US general population: physical QoL $44.4(\mathrm{SD}=12)$ vs. 49.37 ( $\mathrm{SD}=9.75), p=0.002$; mental QoL 49.3 ( $\mathrm{SD}=10.9)$ vs. 49.37 $(\mathrm{SD}=9.75), p=0.891$. No significant differences were found in PCS and MCS when compared with age-appropriate population norms $(p>0.05)(27)$.

Continence. Twenty-eight (82.4\%) patients reported good or perfect continence $(61.8 \%$ and $20.6 \%$, respectively). Mean Wexner Score $(\mathrm{WxSc})$ for our population was $3.97(\mathrm{SD}=3.86)$ out of 20 (Table II) and did not differ between sexes. The percentage of patients who had at least one episode of solid stool or liquid accident in the last month was $17.64 \%(n=6)$ and $23.5 \%(n=8)$ respectively; overall $32.35 \%(n=11)$ had liquid or stool episodes at least once per month. Greater WxSc was associated with worse outcomes in physical and mental QoL: $r=-0.40 ; p=0.019$ and $r=-0.38 ; p=0.025$, respectively.

The patients' own perception regarding having incontinence and the clinical objective measurement (WxSc) differed. Incontinence for stools, as a current symptom, was reported by 7 patients $(24.1 \%)$ with a mean Wexner Score of 9.7. Patients with a WxSc score up to 5 felt free of incontinence and those who reported $\mathrm{WxSc}$ between 6-17 had incontinence. One person with $\mathrm{WxSc}$ of 8 viewed his present condition as free from incontinence.
Sexual functionality. The Overall SFQ score and subscale scores did not differ between males and females (Table IV). Only $24 \%(n=7)$ stated that they were sexually active in the past month. The most common reason for sexual inactivity was lack of a partner (33\%; $n=7)$, followed by "having a physical problem" $(23.8 \%, \mathrm{n}=5)$.

Sexual functioning, QoL, continence and age. The relationship between SFQ, QoL, Wexner Score and age is summarized in Table V. Multiple linear regression analysis was applied for possible risk factors that affect sexual functionality. Poorer function regarding desire and masturbation was significantly associated with increasing age. Better physical QoL was associated with better sexual functioning and arousal. Fewer sexual problems and higher satisfaction were significantly associated with better mental QoL. Additionally, a higher Wexner score, indicating more incontinence symptoms, was associated with a greater medical impact (worse sexual functioning).

Factors influencing patients' decision-making. The patients' TEMS experience, current symptoms, a service-referral evaluation and decision on treatment responses are presented in Table VI.

Twenty-five patients $(86.2 \%)$ would have persisted with their TEMS treatment decision and the majority $(57 \%)$ would travel to have this treatment. The majority of the patients $(71.4 \%)$ did not receive any additional treatment after TEMS. From the remaining $28 \%, 2$ patients had adjuvant radiotherapy and 6 underwent further endoscopic resection.

There was satisfaction with the provided information regarding treatment options by $84.6 \%$ of patients (explained very well by $61.5 \%$ and well by $23.1 \%$ ); two out of three patients stated that post-TEMS experience was in agreement with preoperative information.

Treatment information was understood by the majority of patients $(59.3 \%, \mathrm{n}=16)$ who discussed it thoroughly with 
Koreli et al: Patient Decision-making and Quality of Life Post-TEMS

Table IV. Sexual functioning questionnaire scores: comparison between genders.

\begin{tabular}{|c|c|c|c|c|c|}
\hline & \multicolumn{2}{|c|}{ Male } & \multicolumn{2}{|c|}{ Female } & \multirow[b]{2}{*}{$p$-Value* } \\
\hline & Mean (SD) & Median (IQR) & Mean (SD) & Median (IQR) & \\
\hline \multicolumn{6}{|l|}{ SFQ } \\
\hline Interest & $1.39(0.86)$ & $1.63(0.75-1.88)$ & $0.68(0.96)$ & $0(0-1)$ & 0.118 \\
\hline Desire & $1.85(1.84)$ & $1.33(0-2)$ & $1.04(1.61)$ & $0.33(0-1.67)$ & 0.232 \\
\hline Arousal & $0.95(1.57)$ & $0.25(0-1.25)$ & $0.69(1.16)$ & $0.13(0-1)$ & 0.827 \\
\hline Orgasm & $1.43(1.78)$ & $0.5(0-2.33)$ & $1.43(1.96)$ & $0(0-3.67)$ & 0.848 \\
\hline Satisfaction & $1.08(1.74)$ & $0(0-2.5)$ & $1.3(1.8)$ & $0(0-3.25)$ & 0.617 \\
\hline Activity & $0.52(0.88)$ & $0(0-0.88)$ & $0.72(1.32)$ & $0(0-1.13)$ & 0.965 \\
\hline Relationship & $3.23(1.5)$ & $3.5(1.85-4.46)$ & $3.72(1.14)$ & $4.33(3.7-4.4)$ & 0.558 \\
\hline Masturbation & $0.79(1.3)$ & $0(0-1.67)$ & $0.7(1.17)$ & $0(0-1)$ & 0.929 \\
\hline Problems & $1.39(1.68)$ & $0.75(0-2)$ & $2.13(2.27)$ & $1.58(0-4.25)$ & 0.598 \\
\hline Overall SFQ score & $1.59(1.16)$ & $1.33(0.67-2.2)$ & $1.45(1.18)$ & $1.25(0.51-2.31)$ & 0.772 \\
\hline Medical impact & $3.04(1.63)$ & $3.13(1.6-3.95)$ & $2.96(1.53)$ & $2.6(2.2-3)$ & 0.789 \\
\hline
\end{tabular}

*Mann-Whitney $U$-test. Higher scores indicate better function on all scales except for Medical Impact.

their family. Satisfactory counseling with the clinical nurse specialist (CNS) was reported by 13 patients $(68.4 \%)$; still one third of patients (31.6\%) needed more time for discussion with the CNS. Postoperative pain was rated as 1 (median; IQR=0-5.5) on a scale of 0-10 (no pain at all to very painful), and postoperative bowel disruption was rated acceptable or relieving in $66.7 \%$ of patients $(63 \%$ and $3.7 \%$, respectively).

Patients were asked if they would have the same TEMS surgery in a similar situation. This decision statement was influenced by the patients' experience ( $p=0.003$ ), post-TEMS bowel function of an acceptable and relieving level $(p<0.001)$, a lower Wexner score $(p=0.020)$ and patient experience in agreement with information prior to surgery $(p=0.049)$ (Figure 2).

The patients' TEMS experience was rated on a scale of 0 10 (negative-positive) with a mean of $7.9 \quad(\mathrm{SD}=2.8)$. Treatment satisfaction was associated with family support $(p=0.034)$ and post-TEMS bowel function when acceptable and relieving $(p=0.026)$. Patients who had higher mental QoL score were satisfied more as well $(p=0.003)$. The association of TEMS experience with the quality of written information tended to but did not reach a statistical significance $(p=0.073)$, similarly to the information on treatment options $(p=0.088)$.

Family support influenced the patients' understanding of information, the agreement of treatment experience with preoperative information $(p=0.004)$ and overall satisfaction $(p=0.047)$. However, association with information on what to expect after TEMS did not reach statistical significance $(p=0.059)$. Lower post-operative pain was reported by patients who had more family support ( $p=0.009$ ) (Figure 2).
Table V. Sexual functioning, QoL, continence and age: results of multiple linear regression analysis having SFQ subscales as dependent variables.

\begin{tabular}{lccc}
\hline & $\beta^{*}$ & SE** $^{* *}$ & $p$-Value \\
\hline $\begin{array}{l}\text { Desire } \\
\text { Age }\end{array}$ & -0.017 & 0.007 & 0.039 \\
$\begin{array}{l}\text { Masturbation } \\
\text { Age }\end{array}$ & -0.016 & 0.006 & 0.019 \\
$\begin{array}{l}\text { Satisfaction } \\
\text { MCS }\end{array}$ & 0.011 & 0.005 & 0.029 \\
$\begin{array}{l}\text { Problems } \\
\text { MCS }\end{array}$ & 0.011 & 0.005 & 0.030 \\
$\begin{array}{l}\text { Arousal } \\
\text { PCS }\end{array}$ & 0.010 & 0.004 & 0.012 \\
$\begin{array}{l}\text { Overall SFQ score } \\
\text { PCS }\end{array}$ & 0.007 & 0.003 & 0.014 \\
$\begin{array}{l}\text { Medical impact } \\
\text { Wexner score }\end{array}$ & 0.021 & 0.007 & 0.011 \\
\hline
\end{tabular}

Logarithmic transformations were used due to lack of normality. For orgasm, activity and relationship subscales, no significant associations were found. *Regression coefficient; **standard error; aMCS: mental component score; bPCS-physical component score.

\section{Discussion}

This study showed that provision of adequate information, reliability of information and family support are factors that significantly affect the patients' decision-making in choosing TEMS as opposed to radical surgery for rectal cancer. Also, it demonstrated that the long-term QoL postTEMS leads patients to feel justified regarding their decision on operating choice. 
Table VI. TEMS treatment evaluation.

1. How did you get a referral for a TEMS operation at King
2. Were you offered any other options apart from TEMS
for treatment?
3. If yes, was it

4. Did you feel all the treatment options were explained adequately to you?

5. Did you feel you have enough information to make an informed decision about your treatment of choice?

6. Were you given information of satisfactory quality about TEMS in writing?

7. Did you have a chance to discuss with the clinical nurse specialist about TEMS?

8. Were you told about potential complications and side effects of TEMS?

9. Did you feel you had the chance and enough time to digest the information and discuss with your family?

10. Were you warned about what to expect after TEMS?

11. Was your experience after TEMS in accordance with what was told to you beforehand?

12. How would you rate the level of post-operative pain you experienced after TEMS on a scale of 0-10? Mean (SD), median (range)

13. How would you rate the level of bowel disruption you experienced after TEMS?

14. Did you have additional treatment after TEMS? For example, radiotherapy or further surgery?

15. If you had additional treatment after TEMS did you feel you were adequately warned about the possibility beforehand?

16.If King's is not your local hospital did you find the fact that you had to travel out of area for your treatment acceptable?

17. Would you rate your experience from TEMS surgery as positive or negative on a scale of 0-10? Positive 10, Mean (SD), median (range) 18. Would you have the TEMS surgery again in a similar situation?

$\begin{array}{lc} & \\ \text { I was referred by my local hospital } & 16(57.1) \\ \text { I was referred by my GP } & 8(28.6) \\ \text { King's is my local hospital } & 4(14.3) \\ \text { I researched the internet and asked to be referred } & 0(0) \\ \text { No } & 20(76.9) \\ \text { Yes } & 6(23.1) \\ \text { Radical surgery } & 5(83.3) \\ \text { Radiotherapy } & 0(0) \\ \text { Other } & 1(16.7) \\ \text { Very well } & 16(61.5) \\ \text { Well } & 6(23.1) \\ \text { Not so well } & 3(11.5) \\ \text { Not at all } & 1(3.8) \\ \text { More than enough } & 9(34.6) \\ \text { Enough } & 14(53.8) \\ \text { A little bit } & 2(7.7) \\ \text { Not enough at all } & 1(3.8) \\ \text { No } & 10(38.5) \\ \text { Yes } & 16(61.5) \\ \text { I did discuss with the clinical nurse } & 13(68.4) \\ \text { I needed more time to discuss } & 6(31.6) \\ \text { No } & 10(38.5) \\ \text { Yes } & 16(61.5) \\ \text { A lot } & 16(59.3) \\ \text { Not so much } & 6(22.2) \\ \text { A little } & 5(18.5) \\ \text { Yes, I've been told a lot } & 2(6.9) \\ \text { I haven't been told much } & 2(6.9) \\ \text { I have been told a little } & 9(34.6) \\ \text { I have been told nothing at all } & 6(23.1) \\ \text { It was that I've been told } & 12(57.1) \\ \text { It was different that I've been told } & 2(9.5) \\ \text { I didn't expect things to be like that } & 1(4.8) \\ & 6(25.6) \\ \text { I rather yes } & 7.9(2.8) \\ \text { Might no } & 9(7-10) \\ \text { Definitely no } & 19(65.5) \\ & 6(20.7) \\ \text { Uncomfortable } & 2(7.6) \\ \text { Annoying } & 14(66.7) \\ \text { Acceptable } & 0(0) \\ \text { Relieving } & 7(33.3) \\ \text { Yes, radiotherapy } & 3.1(3.3) \\ \text { Yes, further surgery } & 1(0-5.5) \\ \text { No } & 8(29.6) \\ \text { More than enough } & 1(3.7) \\ \text { Enough } & 17(63) \\ \text { A little bit } & 1(3.7) \\ \text { Not enough at all } & 2(7.1) \\ \text { Maybe } & 6(21.4) \\ \text { Nofinitely applicable } & 20(71.4) \\ & 2(25.0) \\ & 2(25.0) \\ & 4(50.0) \\ & 0(0) \\ & \end{array}$

Table VI. Continued 


\begin{tabular}{|c|c|c|}
\hline & & $\mathrm{N}(\%)$ \\
\hline \multirow[t]{2}{*}{ 19. At the moment do you have symptoms? } & No & $21(75.0)$ \\
\hline & Yes & $7(25.0)$ \\
\hline \multicolumn{2}{|l|}{ 20. On a scale of $0-10$ how severe your overall symptoms are? } & $2(2.7)$ \\
\hline Mean (SD) median (range) & & $0.5(0-4)$ \\
\hline \multirow[t]{2}{*}{ 21. Do you have anal/rectal pain? } & No & $25(92.6)$ \\
\hline & Yes & $2(7.4)$ \\
\hline \multirow{2}{*}{\multicolumn{2}{|c|}{ 22. If you have pain how severe is it on a scale $0-10$ ? Mean (SD) median (range) }} & $1.8(2.2)$ \\
\hline & & $1(0-3)$ \\
\hline \multirow[t]{2}{*}{ 23. Do you have rectal bleeding? } & No & $24(82.8)$ \\
\hline & Yes & $5(17.2)$ \\
\hline \multirow[t]{2}{*}{ 24. If you have rectal bleeding is this } & Occasional & $5(100.0)$ \\
\hline & Regular & $0(0)$ \\
\hline \multirow[t]{2}{*}{ 25. Do you have at the moment incontinence for stools? } & No & $22(75.9)$ \\
\hline & Yes & $7(24.1)$ \\
\hline
\end{tabular}

Questions of high interest to patients and answered by \% of patients were: decision (85.3\%), current symptoms (83\%), post-TEM pain (85.3\%), bowel disruption (79.4\%), family support (79.4\%), referral (82.4\%), additional treatment (82.4\%), information (76.5\%); nurse specialist (55.88\%).

The long term QoL in our patients was found to be no different than in the general population, when corrected for similar age groups. Comparable QoL scores between patients post-TEMS and the general population have been reported earlier $(21,23)$, though with a shorter follow up time; the present study reports the longest reported follow up with a mean follow up of 6.9 years. Lower scores in males and in the whole study population in respect to the physical QoL could be attributed to the development of various comorbidities, unrelated to CRC. Moreover, a significantly impaired QoL has been seen in older (over 75 years) compared to younger patients, 4 years postTEMS (30).

Continence in the majority of our patients after 4-12 years post-TEMS showed a good Wexner score with a mean equal to 3.97. Previous research has shown TEMS to affect short term faecal continence due to rectal dilatation during the operation; this is however temporary (31), as the bowel function returns to the pre-operative levels after 6 months to 1 -year post-operation $(21,32)$. It does not however improve in all cases $(22,33)$.

Prevalence of faecal incontinence (FI) in the general population ranges between $8.3 \%$ and $12.4 \%$, and in the population over 70 years old this condition increases to $14.15 \%-18.39 \%$, showing a strong association with increasing age (based on liquid or solid episodes, at least once per month) $(34,35)$. The self-reported incontinence in the present study was higher compared to the general population, but lower compared to rectal cancer groups after sphincter preserving surgery; in these groups, the reported prevalence was $32 \%$ for liquid and $15 \%$ for solid stool 4 years post-surgery (36), based on incontinence episodes of at least once per week.
We applied the sexual functioning questionnaire (SFQ) because it has a multidimensional construct and assesses sexual functionality within four phases of the sexual response cycle, problems and relationship. Men and women in our sample reported similar sexual functioning in all subscales, with the overall SFQ score being lower than the score obtained by other cancer groups: the SFQ score mean was equal to 2.559 $(\mathrm{SD}=0.773)$ in prostate cancer male patients (37), 3.2 $(\mathrm{SD}=1.0) / 2.1(\mathrm{SD}=1.1)$ in cancer male/female survivals 5 years after haematopoietic cell transplantation (38) and 2.41 $(\mathrm{SD}=0.93)$ in breast cancer female patients (39). However, these were younger populations, the mean age was 61.19 $(\mathrm{SD}=8.16), 47.0(\mathrm{SD}=8.9)$ and 37.8 (27-66 range), respectively.

Age and health problems are negatively associated with many aspects of sexuality, while the experience of sexual dysfunction is generally associated with a poor QoL (40). In support of this, we found increased sexual functioning to be associated with higher physical QoL; and increased mental QoL reflected in higher satisfaction and fewer sexual problems, which is in agreement with Laumann and Waite's study (41), with the exception of their results showing satisfaction in the relationship to be associated with fewer sexual problems. In our study, a poorer sexual desire was associated with ageing. Research evidence shows low scores of sexual desire from $5 \%$ in ages 45-49 to 59\% in ages 80-84 (42).

The continence level $(\mathrm{WxSc})$ as a current condition was reflected in a higher medical impact score (worse sexual functioning) and affected physical and mental QoL as well, all reflecting the age of our sample. As reported previously, incontinence is associated with psychosocial function (43) and impaired QoL after TEMS as well as symptoms like diarrhoea and constipation, which are found to be worse in patients older than 75 years (30). 


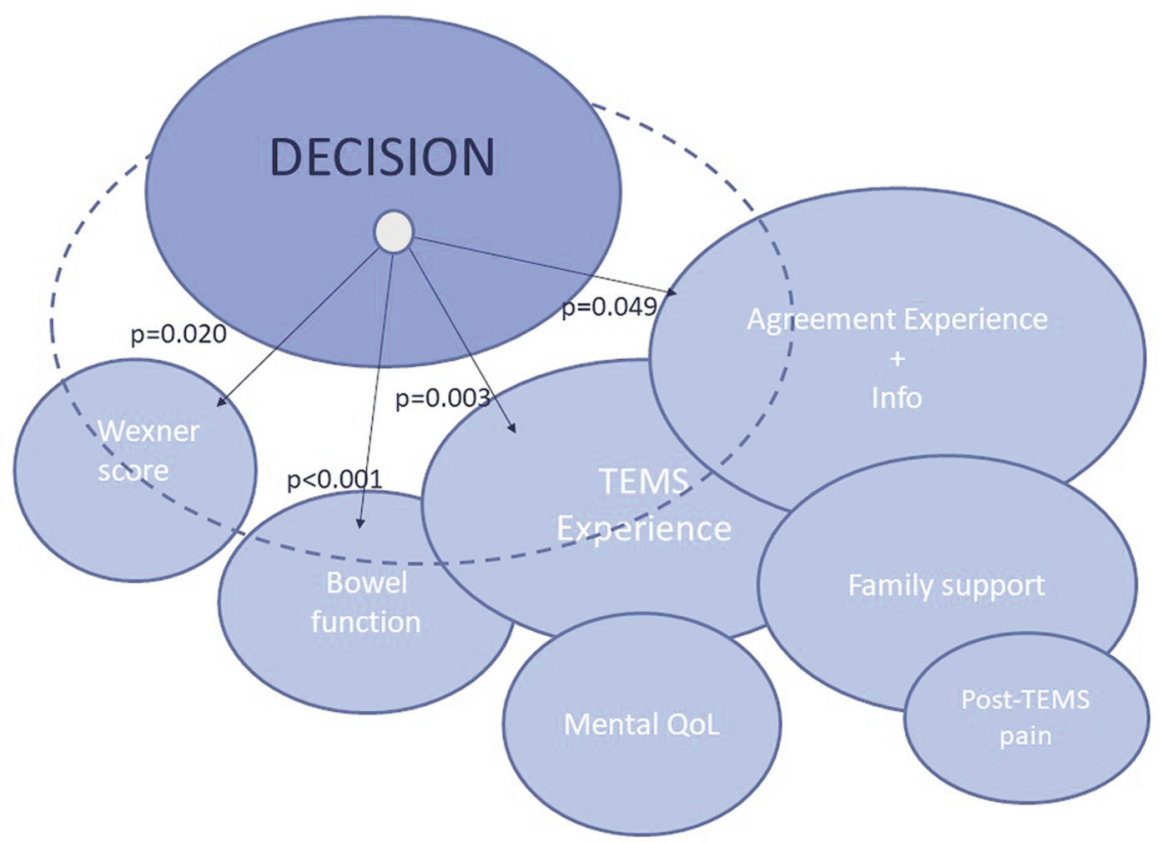

Figure 2. Factors reflecting on decision satisfaction and their interrelations with treatment experience and QoL. Decision: "Would you have the TEMS surgery again in a similar situation?" Agreement Experience and Info: "Was your experience after TEMS in accordance with what was told to you beforehand?" Family support: "Did you feel you had the chance and enough time to digest the information and discuss with your family?" TEMS Experience: "Would you rate your experience from TEMS surgery as positive or negative on a scale of 0-10?"

This study identified that patient experience and its agreement with information prior to surgery as well as bowel function were factors that affect the patients' decision towards TEMS. The positive experience following TEMS surgery in this study confirms that the minimally invasive nature of endoscopic local excision surgery results in increased patient satisfaction. Undoubtedly, the absence of postoperative pain and immobility and the very low rate of complications play a role in patient experience. The satisfactory post-TEMS bowel function justified the patients' choice and confirmed the presumed advantage of TEMS as opposed to radical surgery. Likewise, Planting et al. (22) found 24 of 30 patients were satisfied with TEMS and would prefer the same treatment choice.

There is substantial research evidence that communication and family support are of great importance to clinical outcomes, decisional conflict and treatment choice $(25,26,44$, 45). This study demonstrates that communication in terms of provided information and its understanding had a positive influence on patient experience. More than two thirds of the patients admitted that the treatment they received was exactly as they were told during counselling, which reinforces confidence and a healthy relationship between the healthcare providers and the patient. Moreover, patients who had thorough discussion with their family scored better in treatment experience, postoperative pain and expected outcomes - all factors that affected their treatment choice. Furthermore, the positive association between mental QoL and treatment experience, which in turn was associated with preoperative information, has been seen in other cancer patients as well. Vogel et al. (46) found that patients that were better informed and satisfied for being involved in the decisionmaking process had better QoL, even months after surgery.

Still, one third of our patients remember having been "told little" about "what to expect after TEMS". The patients" retention of information which relates to the postoperative period is poor (47) and might be attributed to the absence of a family member during the information exchange (44). This gap may be filled by an important member of a multidisciplinary team. The role of a colorectal nurse specialist (CNS) is indispensable; research evidence shows that $80 \%$ of patients found talking to a CNS to be helpful (48). We believe that consultation with a CNS is of great importance in information embracing, and the majority of our patients valued it highly; interestingly, one third would prefer to have more time for discussion with a CNS. This important finding, points to more attention and time needed when patients are facing a complex treatment decision.

One limitation of our study is the low response rate at this age group, which resulted in small sample as has been seen elsewhere $(32,33)$. Moreover, participation gradually decreases as time passes on $(21,30)$. Another limitation is 
that there was no pre-assessment on patients' incontinence and sexual functioning. However, with regard to incontinence, the majority of our patients had a good Wexner score and high satisfaction, which resulted in a good overall TEMS experience. Moreover, it has been established that the presence of rectal tumours and also rectal radiotherapy has an effect on faecal continence, and this is why neither we nor other researchers do a routine pre-operative scoring of continence unless there is relevant clinical history. There was an age difference in the sexual functioning assessment norms; however, an age-appropriate comparison was made with the general population.

\section{Conclusion}

This study showed that the factors which are significant to patients in choosing local excision as opposed to radical surgery for rectal cancer are a) availability of adequate information, b) reliability of information, and c) the presence of family support; all reflected in outcomes on postoperative pain, faecal continence, bowel function and treatment experience. In order to enhance the trust of patients, clinicians should incorporate those parameters in everyday practice when assisting patients to reach a decision on the choice of surgery for rectal cancer.

This study found that TEMS is associated with good postoperative long-term QoL, and it is the first to report that post-TEMS QoL leads to patients feeling justified in retrospect regarding their decision on the operating choice.

\section{Conflicts of Interest}

None declared.

\section{Authors' Contributions}

Alexandra Koreli: investigation, data curation, formal analysis, writing of original draft, reviewing. George Briassoulis: methodology, interpretation of the data, writing, reviewing and editing. Michail Sideris: investigation, writing, reviewing and editing. Anastas Philalithis: writing, reviewing and editing. Savvas Papagrigoriadis: conceptualization, study design, methodology, resources, writing, reviewing and editing, supervision.

\section{Acknowledgements}

The Authors are grateful to all patients who participated in this study.

\section{References}

1 Ferlay J, Soerjomataram I, Dikshit R, Eser S, Mathers C, Rebelo M, Parkin DM, Forman D and Bray F: Cancer incidence and mortality worldwide: Sources, methods and major patterns in GLOBOCAN 2012. Int J Cancer 136(5): E359-386, 2015. PMID: 25220842. DOI: 10.1002/ijc.29210
2 Cancer Research UK. Bowel cancer incidence statistics. Cancer Research UK, 2015. Available at: https://www.cancerresearchuk. org/health-professional/cancer-statistics/statistics-by-cancertype/bowel-cancer/incidence [Last accessed on 9th December 2020]

3 Cancer Research UK. Survival I Bowel cancer I Cancer Research UK. Available at: https://www.cancerresearchuk.org/aboutcancer/bowel-cancer/survival [Last accessed on 22nd August 2020]

4 Frattini M, Balestra D, Suardi S, Oggionni M, Alberici P, Radice P, Costa A, Daidone MG, leo E, Pilotti S, Bertario L and Pierotti MA: Different genetic features associated with colon and rectal carcinogenesis. Clin Cancer Res 10(12): 4015-4021, 2004. PMID: 15217933. DOI: 10.1158/1078-0432.CCR-04-0031

5 Benson AB, Venook AP, Al-Hawary MM, Cederquist L, Chen YJ, Ciombor KK, Cohen S, Cooper HS, Deming D, Engstrom PF, Grem JL, Grothey A, Hochster HS, Hoffe S, Hunt S, Kamel A, Kirilcuk N, Krishnamurthi S, Messersmith WA, Meyerhardt J, Mulcahy MF, Murphy JD, Nurkin S, Saltz L, Sharma S, Shibata D, Skibber JM, Sofocleous CT, Stoffel EM, Stotsky-Himelfarb E, Willett CG, Wuthrick E, Gregory KM, Gurski L and Freedman-Cass DA: Rectal Cancer, Version 2.2018, NCCN Clinical Practice Guidelines in Oncology. J Natl Compr Canc Netw 16(7): 874-901, 2018. PMID: 30006429. DOI: 10.6004/ jncen.2018.0061

6 Lopez-Lopez V, Gómez-Ruiz AJ, Eshmuminov D, CascalesCampos PA, Alconchel F, Arevalo-Perez J, Robles Campos R and Parrilla Paricio P: Surgical oncology in patients aged 80 years and older is associated with increased postoperative morbidity and mortality: A systematic review and meta-analysis of literature over 25 years. Surg Oncol 33: 81-95, 2020. PMID: 32561103. DOI: 10.1016/j.suronc.2019.12.007

7 Gavaruzzi T, Giandomenico F, Del Bianco P, Lotto L, Perin A and Pucciarelli S: Quality of life after surgery for rectal cancer. Recent Results Cancer Res 203: 117-149, 2014. PMID: 25103003. DOI: 10.1007/978-3-319-08060-4_10

8 Pieniowski EHA, Palmer GJ, Juul T, Lagergren P, Johar A, Emmertsen KJ, Nordenvall $\mathrm{C}$ and Abraham-Nording M: Low anterior resection syndrome and quality of life after sphinctersparing rectal cancer surgery: A long-term longitudinal followup. Dis Colon Rectum 62(1): 14-20, 2019. PMID: 30394987. DOI: 10.1097/DCR.0000000000001228

9 Rutten HJ, den Dulk M, Lemmens VE, van de Velde CJ and Marijnen CA: Controversies of total mesorectal excision for rectal cancer in elderly patients. Lancet Oncol 9(5): 494-501, 2008. PMID: 18452860. DOI: 10.1016/S1470-2045(08)70129-3

10 Thorpe $\mathrm{G}$ and McArthur M: Social adaptation following intestinal stoma formation in people living at home: a longitudinal phenomenological study. Disabil Rehabil 39(22): 2286-2293, 2017. PMID: 27718730. DOI: 10.1080/09638288. 2016.1226396

11 Buess G, Mentges B, Manncke K, Starlinger M and Becker HD: Technique and results of transanal endoscopic microsurgery in early rectal cancer. Am J Surg 163(1): 63-70, 1992. PMID: 1733375. DOI: 10.1016/0002-9610(92)90254-O

12 Guerrieri M, Gesuita R, Ghiselli R, Lezoche G, Budassi A and Baldarelli M: Treatment of rectal cancer by transanal endoscopic microsurgery: Experience with 425 patients. World J Gastroenterol 20(28): 9556-9563, 2014. PMID: 25071352. DOI: 10.3748/wjg.v20.i28.9556 
13 Jones HJS, Hompes R, Mortensen $\mathrm{N}$ and Cunningham $\mathrm{C}$ : Modern management of $\mathrm{T} 1$ rectal cancer by transanal endoscopic microsurgery: a 10-year single-centre experience. Colorectal Dis 20(7): 586-592, 2018. PMID: 29363859. DOI: 10.1111/codi.14029

14 Papagrigoriadis S: Transanal endoscopic micro-surgery (TEMS) for the management of large or sessile rectal adenomas: a review of the technique and indications. Int Semin Surg Oncol 3: 13, 2006. PMID: 16674824. DOI: $10.1186 / 1477-7800-3-13$

15 Serra-Aracil X, Labró-Ciurans M, Rebasa P, Mora-López L, Pallisera-Lloveras A, Serra-Pla S, Gracia-Roman R and NavarroSoto S: Morbidity after transanal endoscopic microsurgery: risk factors for postoperative complications and the design of a 1day surgery program. Surg Endosc 33(5): 1508-1517, 2019. PMID: 30203205. DOI: 10.1007/s00464-018-6432-5

16 Lezoche G, Baldarelli M, Mario, Paganini AM, De Sanctis A, Bartolacci S and Lezoche E: A prospective randomized study with a 5-year minimum follow-up evaluation of transanal endoscopic microsurgery versus laparoscopic total mesorectal excision after neoadjuvant therapy. Surg Endosc 22(2): 352-358, 2008. PMID: 17943364. DOI: 10.1007/s00464-007-9596-y

17 Sajid MS, Farag S, Leung P, Sains P, Miles WFA and Baig MK: Systematic review and meta-analysis of published trials comparing the effectiveness of transanal endoscopic microsurgery and radical resection in the management of early rectal cancer. Colorectal Dis 16(1): 2-14, 2014. PMID: 24330432. DOI: $10.1111 /$ codi.12474

18 Sgourakis G, Lanitis S, Kontovounisios Chr, Armoutidis V, Korontzi M, Zacharioudakis C and Karaliotas C: Outcomes of transanal endoscopic microsurgery for $\mathrm{T} 1$ and $\mathrm{T} 2$ rectal cancer. Hell J Surg 82(3): 161-171, 2010. DOI: 10.1007/s13126-0100028-4

19 Clermonts SHEM, Köeter T, Pottel H, Stassen LPS, Wasowicz DK and Zimmerman DDE: Outcomes of completion total mesorectal excision are not compromised by prior transanal minimally invasive surgery. Colorectal Dis 22(7): 790-798, 2020. PMID: 31943682 . DOI: 10.1111/codi.14962

20 Levic K, Bulut O, Hesselfeldt P and Bülow S: The outcome of rectal cancer after early salvage TME following TEM compared with primary TME: a case-matched study. Tech Coloproctol 17(4): 397-403, 2013. PMID: 23192705. DOI: 10.1007/s10151012-0950-2

21 Hompes R, Ashraf SQ, Gosselink MP, van Dongen KW, Mortensen NJ, Lindsey I and Cunningham C: Evaluation of quality of life and function at 1 year after transanal endoscopic microsurgery. Colorectal Dis 17(2): O54-61, 2015. PMID: 25476189. DOI: $10.1111 /$ codi.12858

22 Planting A, Phang T, Raval $M$ and Brown C: Transanal endoscopic microsurgery: impact on fecal incontinence and quality of life. Can J Surg 56(4): 243-248, 2013. PMID: 23883494. DOI: $10.1503 /$ cjs.028411

23 Doornebosch PG, Tollenaar RAEM, Gosselink MP, Stassen LP, Dijkhuis CM, Schouten WR, van de Velde CJ and de Graaf EJR: Quality of life after transanal endoscopic microsurgery and total mesorectal excision in early rectal cancer. Colorectal Dis 9(6): 553-558, 2007. PMID: 17573752. DOI: 10.1111/j.14631318.2006.01186.x

24 Marinello FG, Curell A, Tapiolas I, Pellino G, Vallribera F and Espin E: Systematic review of functional outcomes and quality of life after transanal endoscopic microsurgery and transanal minimally invasive surgery: a word of caution. Int J Colorectal Dis 35(1): 51-67, 2020. PMID: 31761962. DOI: 10.1007/ s00384-019-03439-3

25 Cranley NM, Curbow B, George TJ and Christie J: Influential factors on treatment decision making among patients with colorectal cancer: A scoping review. Support Care Cancer 25(9): 2943-2951, 2017. PMID: 28589309. DOI: 10.1007/s00520-0173763-z

26 Street RL, Makoul G, Arora NK and Epstein RM: How does communication heal? Pathways linking clinician-patient communication to health outcomes. Patient Educ Couns 74(3): 295-301, 2009. PMID: 19150199. DOI: 10.1016/j.pec.2008.11.015

27 Ware J: User's manual for the SF-12v2 Health Survey. QualityMetric Incorporated Lincoln, Rhode Island and Health Assessment lab Boston Massachusetts; 2009.

28 Jorge MJN and Wexner SD: Etiology and management of fecal incontinence: Dis Colon Rectum 36(1): 77-97, 1993. PMID: 8416784. DOI: $10.1007 / \mathrm{BF} 02050307$

29 Syrjala KL, Schroeder TC, Abrams JR, Atkins TZ, Brown WS, Sanders JE, Schubert MA and Heiman JR: Sexual function measurement and outcomes in cancer survivors and matched controls. J Sex Res 37(3): 213-225, 2000. DOI: 10.1182/blood2007-06-096594

30 Valsdottir EB, Yarandi SS, Marks JH and Marks GJ: Quality of life and fecal incontinence after transanal endoscopic microsurgery for benign and malignant rectal lesions. Surg Endosc 28(1): 193-202, 2014. PMID: 24026565. DOI: $10.1007 /$ s00464-013-3155-5

31 Mora López L, Serra Aracil X, Hermoso Bosch J, Rebasa P and Navarro Soto S: Study of anorectal function after transanal endoscopic surgery. Int J Surg 13: 142-147, 2015. PMID: 25486265. DOI: $10.1016 /$ j.ijsu.2014.11.021

32 Doornebosch PG, Gosselink MP, Neijenhuis PA, Schouten WR, Tollenaar RAEM and de Graaf EJR: Impact of transanal endoscopic microsurgery on functional outcome and quality of life. Int J Colorectal Dis 23(7): 709-713, 2008. PMID: 18379797. DOI: $10.1007 / \mathrm{s} 00384-008-0442-\mathrm{z}$

33 Cataldo PA, O'Brien S and Osler T: Transanal endoscopic microsurgery: A prospective evaluation of functional results: Dis Colon Rectum 48(7): 1366-1371, 2005. PMID: 15933798. DOI: 10.1007/s10350-005-0031-y

34 Ditah I, Devaki P, Luma HN, Ditah C, Njei B, Jaiyeoba C, Salami A, Ditah C, Ewelukwa O and Szarka L: Prevalence, trends, and risk factors for fecal incontinence in United States adults, 20052010. Clin Gastroenterol Hepatol 12(4): 636-643.e2, 2014. PMID: 23906873. DOI: 10.1016/j.cgh.2013.07.020

35 Sharma A, Yuan L, Marshall RJ, Merrie AEH and Bissett IP: Systematic review of the prevalence of faecal incontinence: Prevalence of faecal incontinence. Br J Surg 103(12): 15891597, 2016. PMID: 27704537. DOI: 10.1002/bjs.10298

36 Lai X, Wong FKY and Ching SSY: Review of bowel dysfunction of rectal cancer patients during the first five years after sphincter-preserving surgery: A population in need of nursing attention. Eur J Oncol Nurs 17(5): 681-692, 2013. PMID: 23871359. DOI: $10.1016 / j$.ejon.2013.06.001

37 Walker LM, King N, Kwasny Z and Robinson JW: Intimacy after prostate cancer: A brief couples' workshop is associated with improvements in relationship satisfaction. Psychooncol 26(9): 1336-1346, 2017. PMID: 27197037. DOI: 10.1002/ pon. 4147 
38 Syrjala KL, Kurland BF, Abrams JR, Sanders JE and Heiman JR: Sexual function changes during the 5 years after high-dose treatment and hematopoietic cell transplantation for malignancy, with case-matched controls at 5 years. Blood 111(3): 989-996, 2008. PMID: 17878404. DOI: 10.1182/blood-2007-06-096594

39 Herbenick D, Reece M, Hollub A, Satinsky S and Dodge B: Young female breast cancer survivors: Their sexual function and interest in sexual enhancement products and services. Cancer Nurs 31(6): 417-425, 2008. PMID: 18987508. DOI: 10.1097/ 01.NCC.0000339252.91194.6c

40 Lindau ST, Schumm LP, Laumann EO, Levinson W, O'Muircheartaigh CA and Waite LJ: A study of sexuality and health among older adults in the United States. N Engl J Med 357(8): 762-774, 2007. PMID: 17715410. DOI: 10.1056/ NEJMoa067423

41 Laumann EO and Waite LJ: Sexual dysfunction among older adults: Prevalence and risk factors from a nationally representative U.S. probability sample of men and women 5785 years of age. J Sex Med 5(10): 2300-2311, 2008. PMID: 18702640. DOI: 10.1111/j.1743-6109.2008.00974.x

42 DeLamater JD and Sill M: Sexual desire in later life. J Sex Res 42(2): 138-149, 2005. PMID: 16123844. DOI: 10.1080/ 00224490509552267

43 Crowell MD, Schettler VA, Lacy BE, Lunsford TN, Harris LA, DiBaise JK and Jones MP: Impact of anal incontinence on psychosocial function and health-related quality of life. Dig Dis Sci 52(7): 1627-1631, 2007. PMID: 17211712. DOI: 10.1007/ s10620-006-9249-3

44 Hubbard G, Illingworth N, Rowa-Dewar N, Forbat L and Kearney N: Treatment decision-making in cancer care: the role of the carer. J Clin Nurs 19(13-14): 2023-2031, 2010. PMID: 20920028. DOI: $10.1111 / j .1365-2702.2009 .03062 . x$
45 van Weert JCM, van Munster BC, Sanders R, Spijker R, Hooft $\mathrm{L}$ and Jansen J: Decision aids to help older people make health decisions: A systematic review and meta-analysis. BMC Med Inform Decis Mak 16: 45, 2016. PMID: 27098100. DOI 10.1186/s12911-016-0281-8

46 Vogel BA, Leonhart R and Helmes AW: Communication matters: The impact of communication and participation in decision making on breast cancer patients' depression and quality of life. Patient Educ Couns 77(3): 391-397, 2009. PMID: 19796910. DOI: 10.1016/j.pec.2009.09.005

47 Turner P and Williams C: Informed consent: patients listen and read, but what information do they retain? N Z Med J 115(1164): U218, 2002. PMID: 12552294.

48 Beaver K, Campbell M, Craven O, Jones D, Luker KA and Susnerwala SS: Colorectal cancer patients' attitudes towards involvement in decision making. Health Expect 12(1): 27-37, 2009. PMID: 19250150. DOI: 10.1111/j.1369-7625.2008. 00515.x

49 Jenkinson C and Layte R: Development and testing of the UK SF-12 (short form health survey). J Health Serv Res Policy 2(1): 14-18, 1997. PMID: 10180648. DOI: 10.1177/1135581969700 200105
Received January 2, 2021

Revised January 22, 2021

Accepted January 27, 2021 